\title{
Advance of Multiplex PCR in Rapid Detecting Transgenic Soybean Oil
}

\author{
Yi Liu, Siya Yin* \\ Baoding Product Quality Supervision and Inspection Institute, Baoding, China \\ Email: ^yinsiya@163.com
}

How to cite this paper: Liu, Y. and Yin, S.Y. (2020) Advance of Multiplex PCR in Rapid Detecting Transgenic Soybean Oil. American Journal of Plant Sciences, 11, 382-392.

https://doi.org/10.4236/ajps.2020.113028

Received: March 25, 2017

Accepted: March 21, 2020

Published: March 24, 2020

Copyright $\odot 2020$ by author(s) and Scientific Research Publishing Inc. This work is licensed under the Creative Commons Attribution International License (CC BY 4.0).

http://creativecommons.org/licenses/by/4.0/

(c) (i) Open Access

\begin{abstract}
Transgenic food safety is a high-profile public health issue in worldwide, especially transgenic soybean (Glycine max L.) oil. To rapidly and effectively detect transgenic components of soybean oil, in the present study, we isolated DNA from transgenic soybean oil by modified method, and employed the multiplex PCR method to identify targeted genes, including CaMV35S promoter, Nos terminator, NPTII, CP4-EPSPS and endogenous gene Lectin. The research aims to build a method which is accurate, rapid and reliable for detection of genetically modified soybeans oil. The targeted gene including DNA was successfully established by the improved method, and then amplified by PCR. Five genes are simultaneously specifically detected. Commercial soybean, genetically modified soy bean and oil were detected with the Multiplex PCR. The improved method of DNA extraction was rapid and accurate to extract high quality total DNA which was amplified by PCR. The method could eliminate the PCR inhibitor. A way of detecting the genetically modified soybean and Oil was set up in this study.
\end{abstract}

\section{Keywords}

Transgenic Soybean Oil, DNA Extraction Method, Multiplex PCR

\section{Introduction}

Food safety is a major global public health problem. Transgenic food is also called genetically modified food (Genetically Modified Food, GMF), and refers to the use of genetic engineering techniques to change the structure of animals, plants and microo rganisms in food production and food additives, including transgenic animals, transgenic plants, micro-products; transgenic plants, genetically modified microorganisms directly or processed goods for raw materials to produce the food and food additives [1] [2]. 
With the development of transgenic technology, genetically modified foods also caused a series of food safety aspects event (incidents): lectin (Lectin) gene to Potato in Scotland; transgenic Bt crops can be harmful to Monarch butterflies. With the development of transgenic technology, genetically modified foods also caused a series of food safety aspects event (incidents): lectin (Lectin) gene to Potato in Scotland; transgenic Bt crops can be harmful to Monarch butterflies. Especially in recent years, with the rapid development of biological technology, genetically modified foods have accounted for a growing proportion of the whole food market since its generation, but the security of genetically modified foods is still a controversial issue.

Multiplex PCR technology is based upon the tradition PCR technology. It is usually used in medicine but rarely used in detection of genetically modified foods. The test of employing Multiplex PCR technology is conducted in a number of targeted gene testing at the same time. Compared with the general one, the credibility of its results is higher. Therefore, for the qualitative transgenic soybeans, multiple PCR test is an ideal detection method. It can not only reduce the testing time and costs, but also improve the efficiency of detection, which would effectively avoid the phenomenon of losing detection [3] [4] [5] [6].

Multiplex PCR is successfully established by targeted genes which include CaMV35S promoter, Nos terminator, NPTII, CP4-EPSPS and endogenous gene Lectin. DNA was isolated by the improved method and then was amplified by PCR. Five genes were detected simultaneously. And, commercial soybean, genetically modified soybean and oil were detected with the Multiplex PCR.

DNA extraction is a crucial step in the process of PCR detection [7]. DNA extraction can determine the level of purity directly, which would influence its results of the PCR detection. High-quality DNA template from transgenic food is the important part of the DNA testing. DNA temple's extraction and purification can not only to meet the requirements of simple, safe and large-scale operation, but also keep the purity of DNA and high rate of requests. At present, there are two main methods, namely, sodium dodecyl sulfate (SDS) and Cetyltrimethyl of the olfactory (CTAB), which can be implemented to extract DNA from transgenic food products.

In order to achieve success of the PCR detection, obtaining high-quality template is the primary key factor. There are many ways, which have been used for the extraction of DNA from genetically modified foods [8]. For instance, Zirnlermann has attempted 9 ways, such as the Wizard kit method, CTAB method, ROSE method, ROSEX method, alkaline method, SDS/proteinase $\mathrm{K}$ method. However, most of them have some major weaknesses, such as overloaded processes, expensive equipments, and unsuitable for carrying on PCR amplification. As the content of protein and fat in the soybeans and oil is very high, it is difficult to extract the DNA template [9] [10]. At present, the most difficulty of using PCR to detect the genetically modified material of GM food is the detection of deep processed GM food, as DNA is largely damaged by the raw transfer materials during the process. 
It is particularly important to improve the reliability of the results of PCR, modify conventional DNA extraction method, and to reduce or eliminate the appearance of inhibitor.

\section{Materials and Methods}

\subsection{Samples and DNA Extraction}

CP4-CPSPS transgenic soybeans (from the Chinese Academy of Agricultural Sciences, Wuhan Research Institute of provide grain and oil crops); Plasmid pBll2I (Saved by the laboratory); Non-genetically modified soybeans (form soybean breeding team of Hebei Agricultural University); Transgenic soybean oil: purchase in the supermarket BaoDing (arawana baand).

\subsection{DNA Analysis}

\subsubsection{DNA Extracting Method from Soybean}

1) Weigh up $200 \mathrm{~g}$ plant material into liquid nitrogen grind to a powder, place into $1.5 \mathrm{ml}$ centrifuge tube which pre-colded by liquid nitrogen.

2) Add the pre-colded at $4^{\circ} \mathrm{C}$ extracting solution into it, mix round intensely, then place it in ice bath for $5 \mathrm{~min} \sim 10 \mathrm{~min}$, and centrifuge for $5 \mathrm{~min}$. at 13,000 $\operatorname{rpm} 4^{\circ} \mathrm{C}$ and discard supernatant.

3) Add $600 \mu \mathrm{l}$ Lysis solution that pre-heated $65^{\circ} \mathrm{C}$ and mixed completely, and water bath at $65^{\circ} \mathrm{C}$ for $30 \mathrm{~min} \sim 60 \mathrm{~min}$.

4) Centrifuge for $10 \mathrm{~min}$. at $13,000 \mathrm{rpm}$, transfer top layer to new Centrifuge tube. Add $3 \mu \mathrm{RNaseA}(10 \mathrm{mg} / \mathrm{ml})$ to it at $37^{\circ} \mathrm{C}$ water bath for $40 \mathrm{~min}$.

5) In the solution, adding equimultiple volume of phenol: chloroform: isoamyl alcohol (25:24:1) and chloroform: isoamyl alcohol (24:1) separate extracting.

6) Centrifuge for $10 \mathrm{~min}$. at 13,000 rpm, transfer top layer to new Centrifuge tube. Add isopropanol with 2/3 vol and NaAc (PH5.6) 1/10 vol., and place at $-20^{\circ} \mathrm{C}$ for $1.5 \mathrm{~h} \sim 2 \mathrm{~h}$, in order to precipitate DNA fully.

7) Centrifuge for $15 \mathrm{~min}$. at $13,000 \mathrm{rpm} 4^{\circ} \mathrm{C}$ and discard supernatant. Wash it with $70 \%$ ethanol, put it out, dry at $55^{\circ} \mathrm{C}$. Add $50 \mu \mathrm{L}$ TE (PH8.0) to melt DNA.

8) Add double distilled water into the DNA solution concentration adjusted to $100 \mathrm{ng} / \mu \mathrm{l}$, store in $-20^{\circ} \mathrm{C}$.

\subsubsection{DNA Extraction Method from Edible Oil}

1) $100 \mathrm{~mL}$ in the beaker added $15 \mathrm{~mL}$ transgenic edible oil and $500 \mu \mathrm{L} \mathrm{TE}$ buffer, using magnetic stirrer mix round $10 \mathrm{~min}$ slowly, at room temperature centrifugal 14,000 rpm, $5 \mathrm{~min}$, removed the upper fats.

2) In the above system, adding the same volume of CTAB Lysis solution and 2 $\mu \mathrm{L}$ RNase solution, surge $3 \mathrm{~s}-5 \mathrm{~s}, 65^{\circ} \mathrm{C}$ water bath $30 \mathrm{~min}$.

3) In the solution, adding equimultiple volume of chloroform: isoamyl alcohol (24:1), standing at room temperature $5 \mathrm{~min}$.

4) Centrifuge for $5 \mathrm{~min}$. at $14,000 \mathrm{rpm}$, transfer top layer to new Centrifuge tube.

5) In the solution, adding $1 \mu \mathrm{L} \sim 2 \mu \mathrm{L}$ Carrier, and add 0.6 times the volume of 
pre-cooling the isopropanol, the reversal of blending, $-20^{\circ} \mathrm{C}$ static $1 \mathrm{~h} \sim 5 \mathrm{~h}$, sufficient precipitation DNA.

6) Centrifuge for $15 \mathrm{~min}$. at 14,000 rpm, removed the upper solution.

7) Washing with 70 percent ethanol precipitation 2 to 3 times, dry at $55^{\circ} \mathrm{C}$, Add $50 \mu \mathrm{L}$ TE (PH8.0) to melt DNA.

8) Add double distilled water into the DNA solution concentration adjusted to $100 \mathrm{ng} / \mu \mathrm{l}$, store in $-20^{\circ} \mathrm{C}$.

\subsection{Design of the PCR System}

By using array design, Oligo, Primer 5 software, design for a Multiplex PCR detection of transgenic soybeans reaction primers.

The polymerase chain reaction (PCR) was performed in $60 \mu \mathrm{L}$ of reaction mixture, composed of $3.5 \mu \mathrm{L}$ of the DNA template was added to $4 \mu \mathrm{L}$ dNTPs, 6 $\mu \mathrm{L} \mathrm{MgCl}, 5 \mu \mathrm{L} 10 \times$ PCR buffer, $0.5 \mathrm{U}$ (U/ul) of Taq polymerase and $1.7-2.0 \mu \mathrm{L}$ of each primer (Table 1). Reactions were carried out in a Master Cycler (Eppendorf). A first step of $5 \mathrm{~min}$ at $94^{\circ} \mathrm{C}$ was followed by 35 cycles of $40 \mathrm{~S}$ at $94^{\circ} \mathrm{C}$, $30 \mathrm{~S}$ at $57^{\circ} \mathrm{C}$, and $30 \mathrm{~S}$ at $72^{\circ} \mathrm{C}$ with a final extension of $6 \mathrm{~min}$ at $72^{\circ} \mathrm{C}$. Amplified PCR products were detected after electrophoresis in $2 \%$ agarose gels stained with ethidium bromide. The PCR reaction was loaded on a $2 \%$ agarose gel and the visualized bands were cut and extracted from the gel (TaKaRa Agarose Gel DNA Purification Kit Ver.2.0, TaKaRa). The purified fragments were cloned into the pMD18-T Vector (TaKaRa) and sequenced.

\section{Results}

\subsection{DNA Extraction Method from Soybean}

First, we used mechanical smashed soybean seed. As soybean seed is very hard, so we used a machine to polish the soybean seed into powder, and extracted the DNA then. In order to reduce the extraction time, in this study CTAB method was used. As a result, its yield and purity met the requirements of PCR reaction (Figure 1). This shows that the quality of DNA extracted was under the premise of rapid completion of a large number of DNA samples from work.

Table 1. Primer pairs used in multiplex PCR in this study.

\begin{tabular}{cccc}
\hline Gene target & Orientation & primer sequence (5'-3') & $\begin{array}{c}\text { Amplified target } \\
\text { DNA(bp) }\end{array}$ \\
\hline \multirow{2}{*}{ CaMV35s } & Sense & AAAGGAAAGGCCATCGTTGAAG & 191 \\
& Antisense & ATAGAGGAAGGGTCTTGCGAAG & \\
\multirow{2}{*}{ NOS } & Sense & AACCCATCTCATAAATAACGTC & 101 \\
& Antisense & AATCTGTTGCCGGTCTTG & \\
Lectin & Sense & ATGGATCTGATAGAATTGAC & 409 \\
& Antisense & CCGAAGCAACCAAACATG & \\
NPT II & Sense & GTCATCTCACCTTGCTCCTG & 142 \\
& Antisense & GGCTTCCATCCGAGTACG & \\
CP4-EPSPS & Sense & CCGGAAAGGCCAGAGGAT & 255 \\
& Antisense & GGCACAAGGGATACAAACC & \\
\hline
\end{tabular}




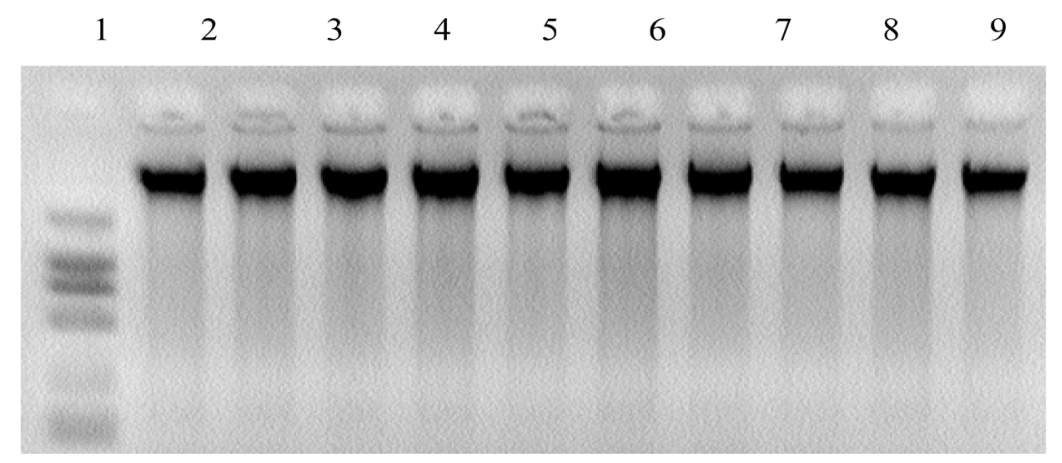

Figure 1. DL 15,000 DNA Marker 1 - 2, 3, 4, 5, 6: transgenic soybean genome 1 $7,8,9,10,11$ : non-transgenic soybean genome.

The improved CTAB the extraction of the soybean genome electrophoresis, with only one outcome, with more clarity, high purity, using the improved method of CTAB soybean genome extract more satisfactory results, can be used for PCR amplification.

\subsection{DNA Extraction Method from Edible Oil}

The improved $\mathrm{CTAB}$ the extraction of the edible oil electrophoresis (Figure 2), with only one outcome, with more clarity, high purity, using the improved method of CTAB edible oil extract more satisfactory results, can be used for PCR amplification.

Only transgenic soybean DNA fragments amplified the CaMV35S promoter gene (Figure 3), non-transgenic soybean DNA fragments not amplified bands.

Only transgenic soybean DNA fragments amplified the NOS terminator gene (Figure 4), non-transgenic soybean DNA fragments not amplified bands.

Only transgenic soybean DNA fragments amplified the CP4-EPSPS gene (Figure 5), non-transgenic soybean DNA fragments not amplified bands.

Both transgenic soybeans and non-transgenic soybeans have amplified the Lectin gene (Figure 6).

Only plasmid pBI121 amplified the gene NPT II, non-transgenic soybean DNA fragments not amplified bands (Figure 7).

Electrophoresis bands are clarity. The Multiplex PCR system is established (Figure 8).

Electrophoresis bands are clarity. There are many primer dimmers in the Figure. Because many primers exist in Multiplex PCR system (Figure 9).

Electrophoresis bands are clarity (Figure 10).

Lane 2 amplified four bands, which NOS terminator (Figure 11), NPT II, the soybean gene (Lectin) for the specific band, to prove the oil is transgenic edible oil, the oil contain foreign genes NOS terminator and the NPT II, the band of 2000 bp may be due to soybean oil during processing by the high-pressure, high temperature and other factors, the genome has been severely damaged, some of the smaller gene fragment of PCR in the process of mutual interference. 


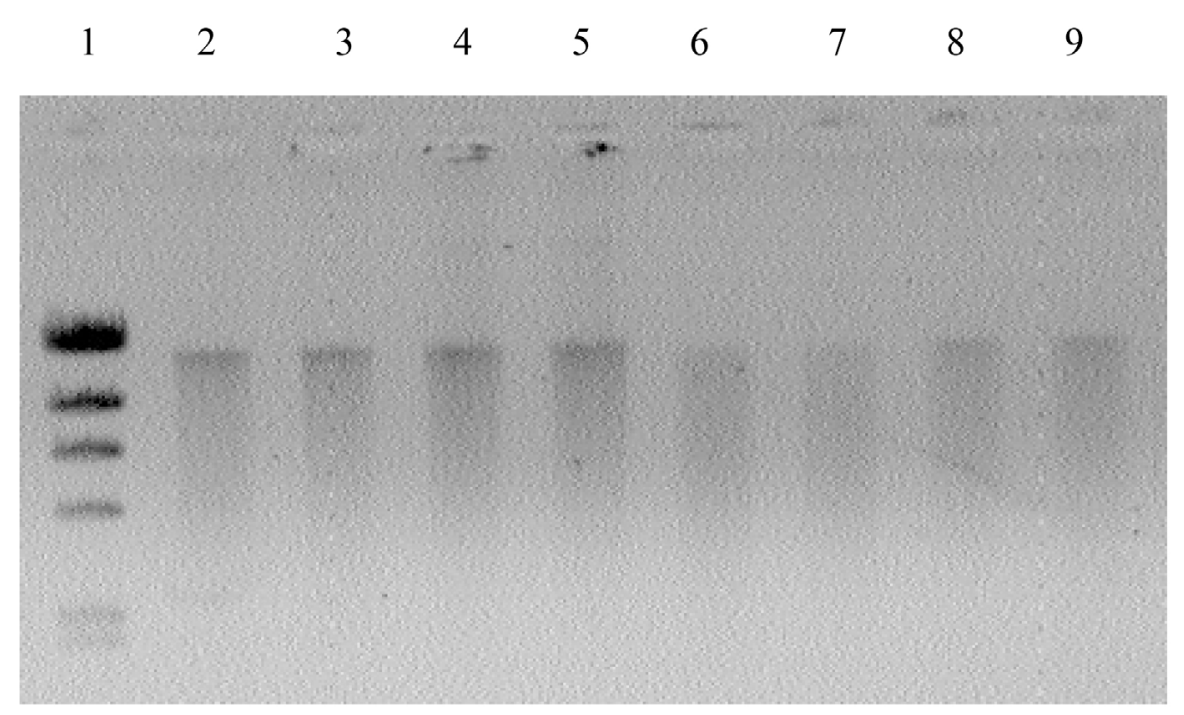

Figure 2. 1-Hind III digest DNA Marker 2-2, 3, 4, 5, 6: transgenic edible oil 2 - 7, 8, 9 non-transgenic edible oil.

\section{Testing for CaMV35S DNA Fragments}

$$
\begin{array}{llllllll}
1 & 2 & 3 & 4 & 5 & 6 & 7 & 8
\end{array}
$$

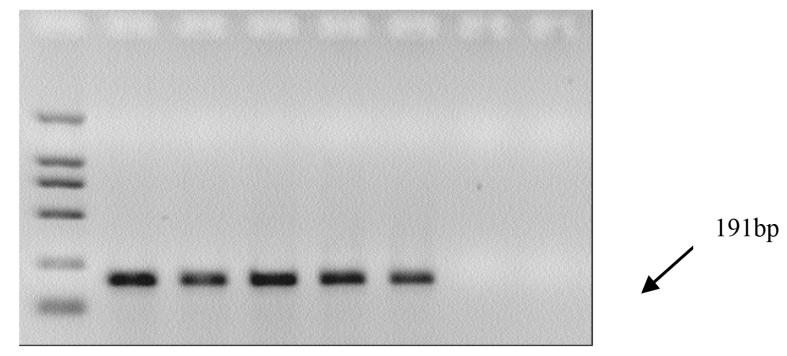

Figure 3. DNA Marker DL 2000 3-2, 3, 4, 5, 6: transgenic soybean DNA fragments $3-7,8$ non-transgenic soybean DNA fragments.

\section{Testing for NOS DNA Fragments}

\section{$\begin{array}{llllllll}1 & 2 & 3 & 4 & 5 & 6 & 7 & 8\end{array}$}

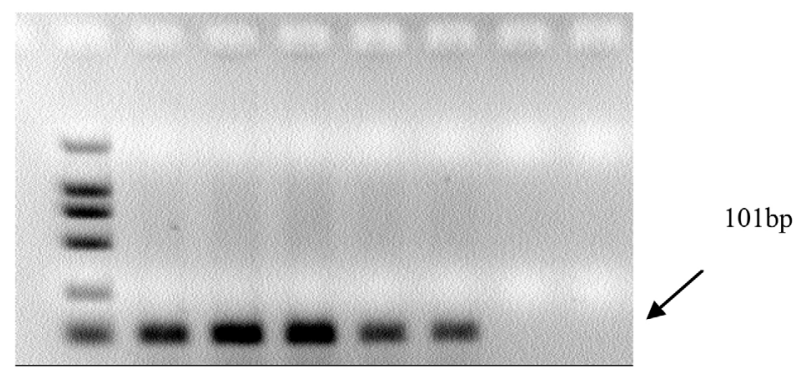

Figure 4. DNA Marker DL 2000 4-2, 3, 4, 5, 6: transgenic soybean DNA fragments $4-7,8$ non-transgenic soybean DNA fragments. 
Testing for CP4-EPSPS DNA Fragments

$\begin{array}{llllllll}1 & 2 & 3 & 4 & 5 & 6 & 7 & 8\end{array}$

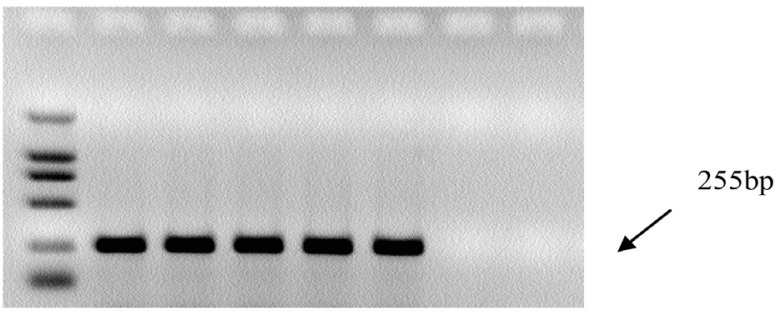

Figure 5. DNA Marker DL 2000 5-2, 3, 4, 5, 6: transgenic soybean DNA fragments $5-7,8$ non-transgenic soybean DNA fragments.

\section{Testing for Lectin DNA Fragments}

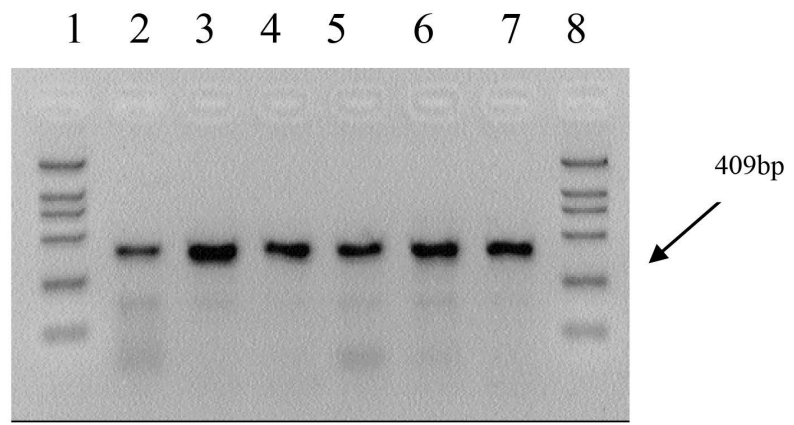

Figure 6. DNA Marker DL 2000 6-2, 3, 4, 5: transgenic soybean DNA fragments $6-6,7$ non-transgenic soybean DNA fragments.

\section{Testing for NPT II DNA Fragments}
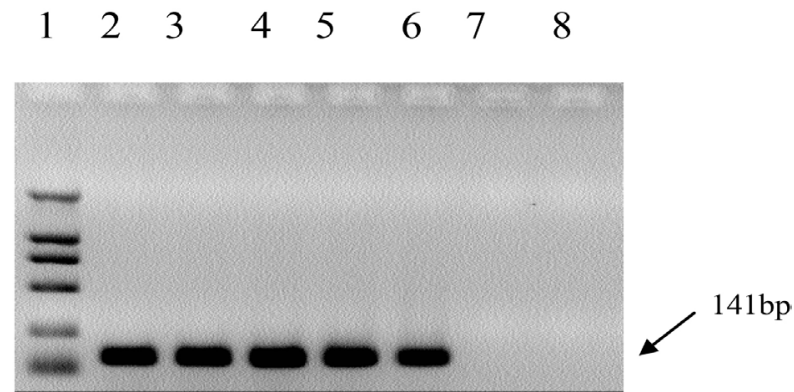

Figure 7. DNA Marker DL 2000 7-2, 3, 4, 5, 6: plasmid pBI121 7 - 7, 8 non-transgenic soybean DNA fragments.

\section{Discussion}

\subsection{DNA Extraction Method from Edible 0il}

After the edible oil is refined and undergone other processing steps, the remnant of nucleic acid was severely damaged into pieces and the content is very low [11] [12] [13]. Therefore, before the start of extraction, DNA can be dissolved in 
The establishment of Multiplex PCR system

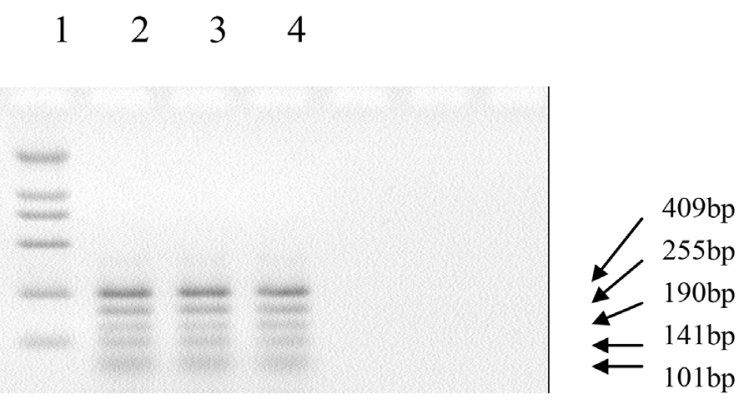

Figure 8. DNA Marker DL 2000 8-2, 3, 4 transgenic soybean DNA fragments.

Multiplex PCR testing for transgenic soybean DNA Fragments

$\begin{array}{llllllllll}1 & 2 & 3 & 4 & 5 & 6 & 7 & 89 & 10 & 11\end{array}$

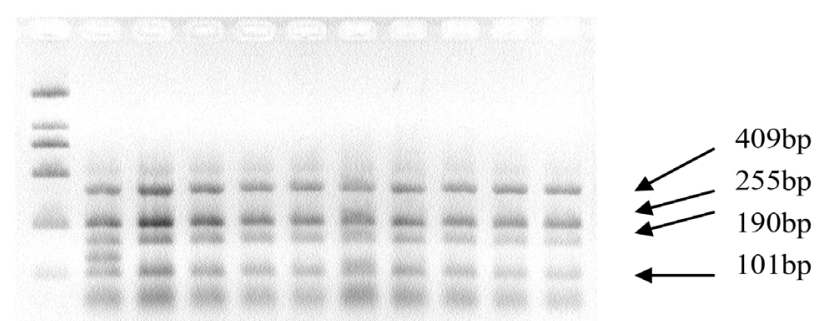

Figure 9. DNA Marker DL 2000 9-2: positive control 9-3, 4, 5, 6, 7, 8, 9, 10, 11 transgenic soybean DNA fragments.

Multiplex PCR testing for soybean (purchase in local market) DNA Fragments
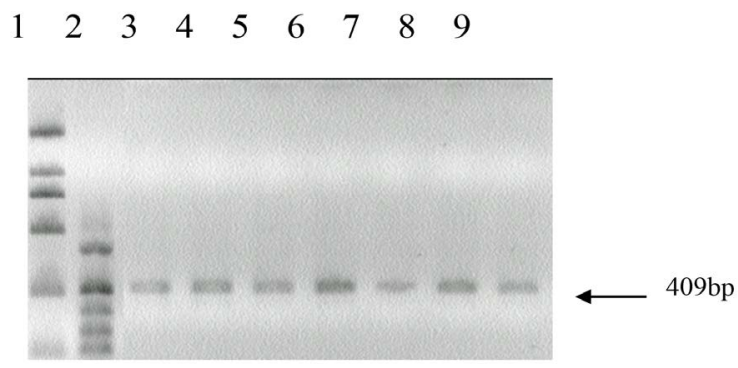

Figure 10. DNA Marker DL 2000 10-2, 10-3, 4, 5, 6, 7, 8, 9 soybean (purchase in local market) DNA Fragments.

Multiplex PCR testing for edible oil DNA Fragments
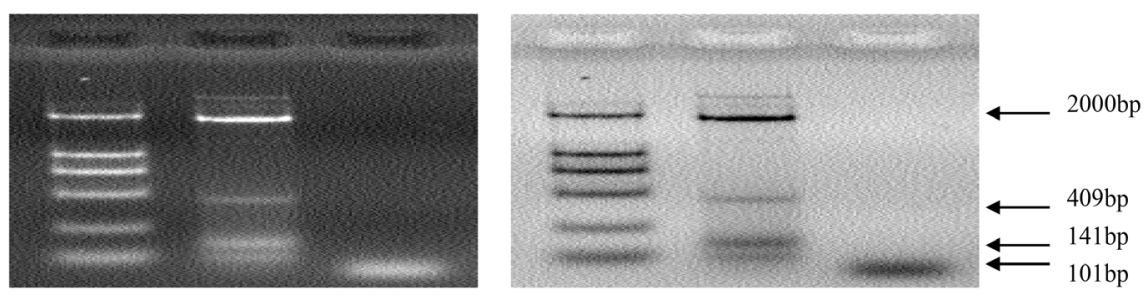

Figure 11. DNA marker DL 2000 11-2, 3 edible oil DNA fragments. 
the water. In the solution of edible oil, it should add a certain volume of a washing solution TE. This step is essential for a successful DNA extraction. The Washing operation practices make a certain impact in the rate of the DNA. The best choice of Carrier DNA is plant, animal, microbial DNA that is far away from the standard DNA. The institute selected non-transgenic soybeans as the Carrier. It has been proved that designed primer does not interfere with each other in the process of establishing system. It does not affect the detection of DNA, and is used as the negative control of PCR reaction.

\subsection{The Design of Primer on Multiple PCR Reaction System}

Primers determine the specificity of PCR products, especially the multiplex PCR reaction system. The choice of each pair of primers is not only related to the amplified results of the DNA fragments, but also involves in the amplification and detection result of the detection of other DNA fragments. The temperature differences cannot be large among the different primers in multiple PCR reaction system. And, the number of complementarily among the primers pairs cannot be too much. Otherwise, primer will be formed primer dimer, and PCR reaction will not carry out, or less than satisfactory response to the results. Therefore, choosing an appropriate primer is the key element of the multiple PCR. According to the different of purpose characters, the types of aim gene are many as well. It has identified four types of foreign gene of usual genetically modified soybeans as the gene detection purpose. Camv35s, NOS, nptII, cp4-epspe and lectin (soybean agglutinin) were used as internal standards to design sequence, and the primer reaction of transgenic soybean system was detected by multiplex PCR. In the process of designing the primer, it would consider the effect between primers and primers, the effect between primers and the DNA template, and give full consideration to the length of the amplified fragment. If the size of fragment is too close, the electrophoresis is hard to detach, and bring difficulties to identify. If the gap between the amplified fragments is large, the establishment of reaction system could be difficult. The test proved that using several pairs of primers by the institute is good for the specificity of knowing transgenic soybeans. The sequencing results of these primers amplified by PCR product and the reported in the literature are as follows: $95 \%, 99 \%, 99 \%$, $100 \%, 100 \%$, which confirmed the amplified PCR product is the targeted product.

Although PCR method is convenient, accurate, rapid and high sensitivity, in the detection of genetically modified food, there are still some questions. Firstly, the genetically modified ingredients of genetically modified food are relatively low. Secondly, there will create false negative, if it cannot effectively rule out the factors of inhibiting the PCR reaction. Thirdly, due to high sensitivity, multiple PCR reaction needs more stringent requirement. In a word, it would be needed to establish a rapid and effective method of extraction of DNA from the genetically modified food. As DNA in the transgenic food reprocessing project is a more serious damage, the extracted DNA from processed foods has always been the bottleneck of the transgenic food detection technology. The only way is to 
find the effective solution of extracting DNA. Then, the detection of transgenic food can be developed rapidly. This method also can be applied to DNA extraction from other Plant oil.

\section{Acknowledgements}

This project was supported financially by grants from the Food Science and Technology College of Agriculture University of Hebei. We thank Dean Wei Zhang for access to transgenic soybeans in their care and Xudong Su for extracting DNA from edible oil. We also thank an anonymous reviewer for helpful comments on an earlier version of the manuscript.

\section{Conflicts of Interest}

The authors declare no conflicts of interest regarding the publication of this paper.

\section{References}

[1] Zhen, H.-J. (1988) The Clinical Immunology Laboratory Evaluation of the Quality during the Decade. Beijing Medical University, Peking Union Medical College Joint Press, Beijing.

[2] Rifkin, J. (2000) Biotechnology Century. Shanghai Science and Technology Education Press, Shanghai.

[3] Herrera-Leo'n, L., Molina, T., Sa1'z, P., et al. (2005) New Mutiplex PCR for Rapid Detection of Isoniazid-Resistant Mycobacterium Tuberculosis Clinical Isolates. Antimicrobial Agents and Chemotherapy, 49, 144-147. https://doi.org/10.1128/AAC.49.1.144-147.2005

[4] Settanni, L., van Sinderen, D., Rossi, J., et al. (2005) Rapid Differentiation and in Situ Detection of 16 Sourdough Lactobacillus Species by Multiplex PCR. Applied and Environmental Microbiology, 71, 3409-3059. https://doi.org/10.1128/AEM.71.6.3049-3059.2005

[5] Vakulenko, S.B., Donabedian, S.M., Voskresenskiy, A.M., et al. (2003) Multiplex PCR for Detection of Aminoglycoside Resistance Genes in Enterococci. Antimicroblal Agents and Chemotherapy, 47, 1423-1426. https://doi.org/10.1128/AAC.47.4.1423-1426.2003

[6] Markoulatos, P., Siafakas, N. and Moncany, M. (2002) Multiplex Polymerase Chain Reaction: A Practical Approach. Journal of Clinical Laboratory Analysis, 16, 47. https://doi.org/10.1002/jcla.2058

[7] Zimmermann, A., Luthy, J. and Pauli, U. (1998) Quantitative and Qualitative Evaluation of Nine Different Extraction Methods for Nucleic Acids on Soya Bean Food Samples. Zeitscheift-fur-Lebensmittel: A Food Research and Technology, 207, 81-90. https://doi.org/10.1007/s002170050299

[8] Zhang, P.P. and Liu, X.H. (2004) Qualitative Detection of Genetically Modified Soybean in Food by Multiplex PCR Analysis. Food Science, 25, 227-230.

[9] Zimmermann, A., Lüthy, J. and Pauli, U. (1998) Quantitative and Qualitative Evaluation of Nine Different Extraction Methods for Nucleic Acids on Soyabean Food Samples. Zeitschrift für Lebensmittel-Untersuchung and Forschung A, 207, 81-90. https://doi.org/10.1007/s002170050299 
[10] Liu, X.-Y. and Tian, S.-Z. (1997) Improve the Method of SDS-CTAB to Extracte DNA from Plants and Microorganisms. Journal of Beijing Forestry University, 19, 100-108.

[11] Chen, Q.S. and Liu, C.Y. (2004) The Basic Principle of DNA Extraction from Soybean. Journal of Northeast Agricultural University, 35, 129-134.

[12] Jin, H., Cheng, Y. and Zhao, X. (2004) Studies on the Technique of Detection of Transgenic Foreign Factors in the Soybean Oil. Acta Agriculturae Boreali Sinica, 19, 24-27.

[13] de la Torre, F., Bautista, R., Cánovas, F.M., et al. (2004) Isolation of DNA from Olive Oil and Oil Sediments: Application in Oil Fingerprinting. Food, Agriculture \& Environment, 2, 84-89. 